\title{
THE SURGICAL TREATMENT OF BRONCHIAL FISTULAS AFTER LUNG RESECTION FOR PULMONARY TUBERCULOSIS
}

\author{
BY
}

\author{
OLIVIER MONOD, GEORGE BABOU, AND JEAN LO \\ From the Hospital-Sanatorium, Chalons sur Marne, France
}

(RECEIVED FOR PUBLICATION AUGUST 22, 1951)

Post-operative fistula is the most distressing complication after lung resection for pulmonary tuberculosis. It occurs after every variety of operation : pneumonectomy, lobectomy, amputation of the apex with or without thoracoplasty.

Fistula is extremely serious after the amputation of the whole lung, and occurs on the main bronchus. Those cases of fistula which we have observed, unless the patient was submitted to re-operation, caused the patient's death, except in one case in which the fistula was due to a suture evacuated by the bronchus. This was easily cured.

Twenty-three fistulas $(20 \%)$ were observed in 112 various lung resections for pulmonary tuberculosis (complete statistics since 1941): seven cases were operated upon, one was cured by endoscopic treatment, and one patient refused the operation. It is the poor results of the operated cases which we are about to describe.

\section{Aetiology}

Bronchial fistula occurred more frequently after resection for tuberculosis (23 cases out of $112,20 \%$ ) than after any other lung resection (4 cases out of $120,3 \%$ ). Fistula was observed after all types of lung resections for tuberculosis. The incidence is summarized in Table I.

TABLE I

Total Number of Bronchial fistulas after Lung Resection for Tuberculosis

\begin{tabular}{|c|c|c|}
\hline $\begin{array}{c}\text { No. of } \\
\text { Fistulas }\end{array}$ & $\begin{array}{c}\text { Number and Type of } \\
\text { Operations }\end{array}$ & $\begin{array}{l}\text { Period of } \\
\text { Reference }\end{array}$ \\
\hline $\begin{array}{l}5 \\
6 \\
6\end{array}$ & 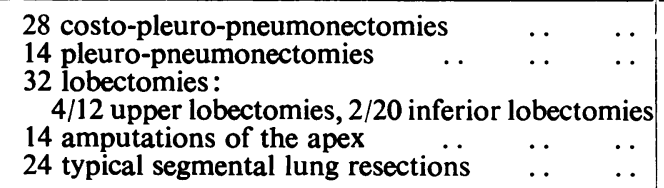 & $\begin{array}{l}1949-51 \\
1947-51 \\
1941-51 \\
1944-8 \\
1950-1\end{array}$ \\
\hline Total & $112(20 \%)$ & \\
\hline
\end{tabular}

Fistula was a sequel of pyothorax, isolated cavities, and residual cavities after thoracoplasty. More important aetiologically, however, is the phase of the tuberculosis for which the lung resection was carried out. Koch's bacilli were found in the sputum of all the patients who developed fistulas after lung resection. All nonbacillary lesions, except " tuberculoma " and isolated cavities, for which a pulmonary 
resection was done, healed without fistula, except in one case. Fistula occurs more frequently in diffuse, active lesions with a high sedimentation rate, than in other lesions. It is important to appreciate that an oscillating temperature and a high sedimentation rate can result from pleural retention and not from a pulmonary lesion.

All our patients had received large doses of streptomycin, not only during the preoperative period, but in the course of their illness at an epoch when the contraindications to streptomycin therapy alone were not yet established. At the present time our patients are operated on without having received streptomycin.

It seemed that the condition of the bronchus had less effect on the development of fistulas than might have been thought at first ; indeed, we considered bronchial stenosis as a favourable element, as it can help the suture of the bronchus. We have observed cicatrizations without fistulas of the bronchus occurring in conjunction with active lesions of the mucous membrane (oedema or superficial ulcerations) and fistulas have also occurred in healthy bronchi. We have been careful, since 1943, to divide the bronchus at its origin : at the tracheal carina in pneumonectomy, and at the lobar carina in lobectomy. In spite of this, we observed fistulas. We believe that the reasons were (1) doubtful indications at the beginning of our practice ; $(2)$ operations performed in spite of serious bronchial lesions; (3) the absence of streptomycin until 1947. But the close section of the bronchus renders the suture difficult in the case of fistula. It is more convenient to have a small bronchial stump ( 2 to $3 \mathrm{~mm}$.). On the other hand, we do not believe, if indications are otherwise favourable, that the preservation of this stump favours the development of a fistula later on. This is why, at the present time, we are trying this technique without having a great experience of it.

\section{Pathological Anatomy}

The fistula may be incomplete, comprising part of the lumen of the bronchus, or total. If a certain length of bronchus has been left at operation there will be room for a pollard and a correct suture. If, on the other hand, the fistula occurs at the section of a main bronchus at its origin, a lateral wound of the trachea results and more arduous treatment is necessary.

The presence or absence of lung in the operative hemithorax is important. If part of the lung is left, it can be liberated by decortication and its re-expansion obtained in the cavity ; the lung is the most satisfactory prosthesis after a lobectomy. If, on the contrary, the pneumonectomy has been total, a pleural cavity will persist after operating upon the fistula.

The physiopathology of bronchial fistula explains certain additional complications which are peculiar to it and occur when the fistula is large and accompanied by a parietal wound; an almost total aphony is then observed. Air leaks from the fistula and the patient cannot raise sufficient strength to make the vocal folds vibrate.

Dyspnoeic accidents are observed when the mediastinum is mobile; it shifts at the time of inspiration towards the healthy side, and the lung does not inflate or deflate during expiration. Real asphyxia can occur. One of our patients practically suffocated every time his dressing was changed. These disorders are less serious if the mediastinum is rigid, and mechanical accidents are not observed in fiptulas of small lumen. 


\section{Clinical Data}

Bronchial fistulas can be classified according to the date of their appearance after resection. Some appear immediately, others become evident 10 or 15 days after operation, and others after several months. But it seems to be more important to distinguish the fistulas according to the mechanism of their origin. Some are the consequence of a bronchial suture which does not hold, and occur within the immediate post-operative course. Others have an indefinite cause and appear later. Two phenomena can create the secondary or belated reopening of a bronchial stump which had healed by prime intention. Sometimes it is due to tuberculous lesions of the bronchial wall itself, which evolve on their own and reopen a scar. Sometimes, and within our experience it is the most frequent cause, a purulent pleural effusion collects within the weeks or the months following the operation, especially when the re-expansion of the lung did not occur immediately, and tracks, sometimes towards the exterior, sometimes towards the sectioned bronchus, but in the end it often travels in both directions.

TABLE II

Frequency of Fistulas According to the Published Statistics

\begin{tabular}{|c|c|c|c|c|}
\hline Authors & & $\begin{array}{l}\text { Number of Lung } \\
\text { Resections }\end{array}$ & $\begin{array}{c}\text { Number of } \\
\text { Bronchial Fistulas }\end{array}$ & Percentage \\
\hline $\begin{array}{l}\text { Bérard et al. (1950) } \\
\text { Clagett (1948) } \\
\text { Mathey } \text { et al. }(1950) \\
\text { Sweet and Le Brigand (1948) } \\
\text { Bailey (1947) } \\
\text { Overholt and Wilson (1945) } \\
\text { Jones (1945) } \\
\text { Sellors (1950) } \\
\text { Monod } \text { et al. }(1951)\end{array}$ & $\begin{array}{l}\cdots \\
\cdots \\
\cdots \\
\cdots \\
\cdots \\
\cdots \\
\cdots \\
\cdots\end{array}$ & $\begin{array}{r}120 \\
29 \\
60 \\
63 \\
80 \\
127 \\
32 \\
78 \\
112\end{array}$ & $\begin{array}{r}16 \\
2 \\
5 \\
2 \\
7 \\
12 \\
4 \\
14 \\
23\end{array}$ & $\begin{array}{l}13 \cdot 3 \\
7 \\
8 \cdot 3 \\
3 \\
11 \\
8 \\
13 \\
18 \\
20\end{array}$ \\
\hline
\end{tabular}

The clinical manifestations of the fistula are different according to whether a small fistula is involved or a large bronchopleural communication. The two main symptoms are expectoration and the escape of air through the fistula. Expectoration is more or less profuse according to the effusion it drains. In doubtful cases, the diagnosis will sometimes be confirmed by the methylene blue test. In the case of a parietal wound, the escape of air through the fistula will be heard when the patient contracts his chest and holds his nose.

Dyspnoea, the pulmonary concomitant element being put aside, is directly proportional to the lumen of the fistula. If the fistula is wide and the suppurating pleural sac is in communication with the exterior of the thoracic wall, the patient is unable to talk and cough as long as the parietal opening is not closed off. The process resembles that which occurs during anaesthesia when a bronchial blocker has not been used on the healthy side, and when the sectioned bronchus is opened without first being clamped.

Some fistulas are latent and only bronchoscopy can show the opening, which is situated at the end of the bronchial sectioned stump.

Bronchial fistulas seldom close spontaneously. Fistulas affecting a small bronchus, such as those we observed after amputation of the apex (Tuffier's oper- 
ation) showed some tendency to close, as did those (Monod, Warnery, Lespinasse, and Leibinson, 1945) following a speleotomy, but we never observed that large fistulas of a lobar or of a main bronchus healed spontaneously. One lobar fistula only, maintained by a silk thread, healed rapidly after bronchoscopy. But this fistula was mechanical and not tuberculous. Such mechanical fistulas, which healed when the suture had been expelled, were twice observed following pulmonary resection for cancer.

\section{RESULTS}

The variety of treatment we have tried, the difficulty in performing the operations we suggest, and the fact that we have had to re-operate sometimes two or three times upon the same patient, prove that we advocate no particular therapy and are unable to advise any special method standing great chances of success. Still, we believe it may be useful to underline the poor results obtained if only to provoke other publications teaching us more adequate treatments, and especially a more efficient prophylaxis of this distressing complication.

We carried out plastic parietal operations three times for resection of reossification and pneumolysis. The patients had small fistulas consecutive to partial lobectomies, but only a small and localized pleural sac existed communicating with the fistula and with the skin. These three attempts were failures.

TABLE III

RESUlts OF THE OPERATIONS

\begin{tabular}{|c|c|c|c|c|c|}
\hline \multicolumn{3}{|c|}{ Operation* } & $\begin{array}{l}\text { No. of } \\
\text { Cases }\end{array}$ & $\begin{array}{l}\text { No. of } \\
\text { Healed }\end{array}$ & Failures \\
\hline $\begin{array}{l}\text { Plastic parietal } \\
\text { Dissection of } \\
\text { the fistula, } \\
\text { freshening } \\
\text { up, suture }\end{array}$ & $\begin{array}{l}\text { operations } \\
\left\{\begin{array}{l}\text { simple suture } \\
\text { suture + myoplasty } \\
\text { suture + placental grafting } \\
\text { complement of lobectomy }\end{array}\right.\end{array}$ & $\begin{array}{l}\cdots \\
\cdots \\
\cdots \\
\cdots \\
\cdots\end{array}$ & $\begin{array}{l}3 \\
2 \\
4 \\
2 \\
1\end{array}$ & $\begin{array}{l}0 \\
2 \\
1 \\
1 \\
1\end{array}$ & $\begin{array}{l}3 \\
0 \\
3 \\
1\end{array}$ \\
\hline
\end{tabular}

* 12 operations on 6 patients: 1 operated 4 times, 1 operated 3 times, 1 operated twice, 3 operated once.

Large fistulas of the main bronchus do not allow much choice as regards the method of operation. We believe that a direct operation on the fistula should be carried out. Thus, in all our cases, we sutured the fistula after dissecting the bronchus and freshening up its extremity. The dissection in one case was so difficult that the suture was undertaken without freshening up and was unsuccessful. In four cases after freshening up we added a myoplasty, made either from an intercostal peduncled graft, or from a piece of latissimus dorsi muscle (free myoplasty). We had one success. In two cases we added a graft of a cube of placenta to the freshened suture, with one success. We obtained two successes in two cases with the simple suture with freshening up. In one case we undertook successfully a segmental lobectomy of the upper lobe where the fistula was located. All our operations were carried out on patients who, as it happened, were streptomycinresistant.

In our attempts to cure fistulas, we performed 12 operations on six patients : on one, four operations, on another, three, on a third two, and on three patients one 
was sufficient. This indicates the frequency of failures. We had five successes out of 12 operations on six patients, when we cicatrized the fistula. Two of our patients died several months later from the effects of a contralateral lesion or another tuberculous focus.

On the whole, prognosis is still comparatively favourable for small fistulas when a considerable quantity of lung has been left. On the other hand, fistulas of the main bronchus after a total pneumonectomy are extremely serious. Let us recall what de Winter (1949) writes :

“. . . but, more frequent and more redoubtable than the parietal fistulation is the rupture of the bronchial suture. It generally means lingering death for the patient from cachexia : even the most radical thoracoplasty could not obstruct the huge thoracic empyema space, and the odds on recovery of this large bronchial fistula were practically nil."

\section{Surgical TeChNiQue}

A serious drawback to operations for bronchial fistula is that they are difficult and unpredictable. The approach has to be wide. We have always practised Crafoord's wide posterolateral approach, or a similar incision. The first difficulty is the dissection of the bronchus. Sometimes an anatomically healthy zone favours the approach. But it is seldom seen. In any case, one must get at the bronchial wall bordering the fistula. One should explore the neighbouring organs in order to dissect the bronchus ; it is well known how difficult it is to dissect arteries, veins, and bronchus in an infected region and, still more so, in a region which has already been dissected at the time of the first operation.

The tracheo-bronchial wall of the upper vena cava should be released in front and the wall of the pulmonary trunk below and within, in cases of right main bronchus fistulas. In one case we observed the arch of the azygos vein had dropped beneath the fistula. (This was a case in which there was a total fistula ; the bronchus had been cut on a level of the trachea and the aperture was equivalent to a lateral wound of the trachea.) The wall of the large veins is no longer bluish and cylindrical, but white, and may be mistaken for a pleuro-cellular inspissation. In a fistula of the left main bronchus the retracted fistula was found far from the concavity of the aortic arch. A first attempt to dissect the parts was unsuccessful. It was only at the second attempt and after disengaging the arch of the aorta that we could reach the trachea (Monod and Kateb, in the press).

The vagus nerve will be found on both sides in the posterior lip of the fistula ; it should be identified higher up and separated from the bronchial wall. The bronchial and intercostal vessels should be treated with care.

When dissected, the bronchus should be freshened until distinct bleeding occurs at the end. The suture itself is not easy. The bronchus, when released, recedes from view. The stitches are not always impervious. Pleuralization is more often than not impossible in a thoracic cavity stripped of its pleura, and we believe that myoplasties should be carried out using pediculated muscle from an intercostal space, free strips of the rhomboid, or of the latissimus dorsi muscle. As indicated by Razemon, fresh placenta seems to us to be a favourable material for speleotomies.

\section{INDICATIONS FOR SURGERY}

We believe that, in spite of failures, one should first perform a thoracoplasty in the case of fistulas following lobectomies, and especially if the pleural sac is of a 
moderate size. We base this opinion on the analogy of perforated extrapleural fistulas, which are frequently cured by thoracoplasty. A complete decortication of the lung should be added. One should operate directly on the fistula if a thoracoplasty has been carried out previously. The pollard and the suture are facilitated when a utilizable stump exists. If an atypical partial resection has originally been performed (Tuffier's amputation of the apex), a typical segmental resection should be carried out and the remaining fistula treated by dissection lobectomy.

In the case of a fistula of the main bronchus, suture should be attempted if there is enough tissue ; otherwise, one is reduced to grafting to obstruct the fistula. The mobilization of the arch of the aorta should be used in order to approach the point of origin of the main left bronchus. Results are disappointing, but the seriousness of each case is such that attempts to close the fistula are legitimate.

To avoid, as far as possible, post-operative suppurating effusions and fistulas, the following rules were adopted in surgery for lung resection for pulmonary tuberculosis. (1) Resections for pulmonary tuberculosis, lobectomies and pneumonectomies, were only carried out when a thoracoplasty was impossible or distinctly contraindicated. Large cavities of the lower lobe, tight bronchial stenosis, carcinoma occurring as a complication, and bronchiectasis with Koch bacillus are unquestionable indications for resection. We believe that pyothorax is not always a direct indication for lung resection. Thoracoplasty has, in these cases, solid indications. (2) Very small and absolutely cured lesions (except tuberculoma and isolated cavities) are especially suitable for segmentary lobectomy if all conditions are fulfilled. (3) A lung resection should, with certain exceptions, only be carried out if the patient is streptomycin-sensitive. (4) If the pleura is not absolutely free and healthy, it should be removed with the lung. (5) We believe it safer to perform a costal resection at the same time as the lung resection: we do an extensive plastic operation, as performed by M. Bérard after pneumonectomy, and small upper plastic procedures when a lobectomy of the apex is carried out. These rules should only be applied to lung resections for pulmonary tuberculosis.

We wish to thank MM. Soulas, Lemoine, Paillas, and Triglianos, who carried out the bronchoscopies.

\section{BiBLIOGRAPHY}

Bailey, C. P. (1947). J. thorac. Surg., 16, 328.

Bérard, M., Sournia, J. C., and Jaubert de Beaujeu, M. (1950). Rev. Tuberc., Paris, $14,818$.

Clagett, O. T., and Seybold, W. D (1948). Proc. Mayo Clin., 23, 81.

Jones, J. C. (1945). Amer. Rev. Tuberc., 51, 55.

Mathey, J., Oustrieres, G., and Tobé, F. (1950). Rev. Tuberc., Paris, 14, 458.

Monod, O., Babou, G., Kateb, E., and Ghazi, S. (1951). Poumon, 7, 51. and Kateb, E. J. thorac. Surg. In the press.

- Warnery, M., Lespinasse and Leibinson (1945). Rev. Tuberc., Paris, 9, 252.

Overholt, R. H., and Wilson, N. J. (1945). Amer. Rev. Tuberc., 51, 18.

Sellors, T. Holmes (1950). Quoted by Bérard, M., Sournia, J. C., and Jaubert de Beaujeu, M., 1950, Rev. Tuberc., Paris, 14, 818.

Sweet, R. H., and Le Brigand, H. (1948). Poumon, 4, 46.

Winter, L. de (1949). Acta tuberc. belg., suppl. 40 (spec. no. pt. 1), 101. 